Theor. Appl. Climatol. (2007)

DOI 10.1007/s00704-007-0335-Z

Printed in The Netherlands

Theoretical and Applied Climatology

\footnotetext{
${ }^{1}$ State University of Amazonas (UEA), Manaus, AM, Brazil

${ }^{2}$ National Institute for Space Research (INPE), São José dos Campos, SP, Brazil

${ }^{3}$ National Institute for Amazonia Research (INPA), Manaus, AM, Brazil
}

\title{
Modeling the impacts of land cover change in Amazonia: a regional climate model ( $\mathrm{RCM})$ simulation study
}

\author{
F. W. S. Correia ${ }^{1,3}$, R. C. S. Alvalá ${ }^{2}$, A. O. Manzi ${ }^{3}$ \\ With 7 Figures \\ Received 23 January 2007; Accepted 1 June 2007; Published online 12 October 2007 \\ (C) Springer-Verlag 2007
}

\begin{abstract}
Summary
The numerical regional model (Eta) coupled with the Simplified Simple Biosphere Model ( $\mathrm{SSiB}$ ) was used to investigate the impact of land cover changes on the regional climate in Amazonia. Four 13-month integrations were performed for the following scenarios: (a) no deforestation, (b) current conditions, (c) deforestation predicted for 2033, and (d) large scale deforestation. All initial and prescribed boundary conditions were kept identical for all integrations, except the land cover changes. The results show that during the dry season the post-deforestation decrease in root depth plays an important role in the energy budget, since there is less soil moisture available for evapotranspiration. In all scenarios there was a significant increase in the surface temperature, from $2.0^{\circ} \mathrm{C}$ in the first scenario, up to $2.8^{\circ} \mathrm{C}$ in the last one. In both the scenarios (b) and (c), the downward component of the surface solar radiation decreased due to an increase in the cloud cover over the deforested areas, which contributed to a further reduction of the net radiation absorbed at the surface. The cloud mechanism, where an increase in albedo is balanced by an increase in downward solar radiation, was not detected in any of these scenarios. In scenarios (a), (b) and (c), a negative feedback mechanism was observed in the hydrological cycle, with greater amounts of moisture being carried to the deforested areas. The increase in moisture convergence was greater than the reduction in evapotranspiration for both scenarios (b)
\end{abstract}

Correspondence: F. W. S. Correia, State University of Amazonas, Darcy Vargas Avenue, 1200 Manaus, AM, Brazil, e-mail: fcorreia@ uea.edu.br and (c). This result, and the meso-scale thermodynamic processes caused an increase in precipitation. A different situation was observed in the large-scale deforestation scenario (d): a local increase of moisture convergence was observed, but not sufficiently intense to generate an increase in precipitation; the local evapotranspiration decrease was dominant in this scenario. Therefore, the partial deforestation in Amazonia can actually lead to an increase in precipitation locally. However, if the deforestation increases, this condition becomes unsustainable, leading to drier conditions and, consequently, to reduced precipitation in the region.

\section{Introduction}

A comprehensive assessment of the world's forests, released by the Food and Agriculture Organization of the United Nations (FAO 2000), indicates that forested areas continued to decline significantly in the 1990s. According to FAO's analysis, the deforestation is concentrated in the developing world, which lost approximately 62 million hectares between 1990 and 1995. Over the last few decades, Brazil has witnessed various transformations in land use and land cover, including, for example, high rates of deforestation in the northern, northeastern and central regions and the expansion of agricultural lands in the southeastern and southern regions. These transformations in land cover, associated with land-use 
F. W. S. Correia et al.

practices, exert a great influence on the hydrology, climate, and biogeochemical cycles of these regions (Nobre et al. 1991; Dirmeyer and Shukla 1994; Sud et al. 1996a, b; Hahmann and Dickinson 1997; Voldoire and Royer 2004).

The Amazon Forest is the largest continuous tropical forest ecosystem in the world. Deforestation is rapidly progressing in the Amazon basin, particularly in its southeastern area ("Brazilian arc of deforestation"), encompassing the states of Rondônia, Pará and Mato Grosso. The rate of gross deforestation in Legal Amazon (the Brazilian part of the Amazon basin) from 2003 to 2004 was $26,130 \mathrm{~km}^{2}$. For over a decade, the Brazilian National Institute for Space Research (INPE, Instituto Nacional de Pesquisas Espaciais) has been conducting satellite imagery analysis to monitor the evolution of the extent and rate of gross deforestation in the Legal Amazon. According to INPE, by 2004 approximately $18 \%$ of Brazil's primary forests were converted to pasture and agricultural land (INPE 2005). These have been the main forms of land use changes in Amazonia, although other land-cover-changes such as selective logging, the conversion of savanna (cerrado) to agricultural areas (for example, soybean farming in Mato Grosso state), and the abandonment and regrowth of forests also should be noted. All these land use and land cover changes in Amazonia raise one key scientific question: How will the regional climate of Amazonia change in response to changes in land use? Another important question raised is the need to consider a more realistic view of the Amazonian land cover, in order to verify any detected climate changes. To answer these questions, several studies used General Circulation Atmosphere Models (GCMs) to evaluate the effect of large-scale deforestation in the climate of Amazonia (Dickinson and Kennedy 1992; Manzi and Planton 1996; Zhang et al. 1996a, b; Lean and Rowntree 1997; Costa and Foley 2000; Kleidon and Heinmann 2000; Voldoire and Royer 2004). Voldoire and Royer (2004) integrated a GCM for a period of twenty-nine years using the land cover distribution provided by the IMAGE2.2 land cover map for 1980. Several integrations were performed, maintaining all the same boundary conditions, but replacing all tropical forests in Amazonia, equatorial Africa and Indonesia by grazing land, thus resulting reductions of pre- cipitation, evapotranspiration, and moisture convergence over Amazonia when pasture replaced forest. However, Manzi and Planton (1996) and Lean and Rowntree (1997) found different results in their simulations, specially an increase of the moisture convergence. Unfortunately, GCMs are not well provided to simulate the partial deforestations, which are presently occurring in Amazonia; so, they are unable to estimate accurately the effects of partial deforestation on precipitation. Therefore, the use of high-resolution regional models, which represent in greater detail the hydrodynamic processes and their interactions with the continental surface processes, should be more efficient. Analytical and numerical studies using mesoescale (regional) models have shown that the horizontal heterogeneity in the turbulent surface sensible and latent heat fluxes can produce strong meso-scale circulations (Avissar and Liu 1996; Silva Dias and Regnier 1996; Avissar and Schmidt 1998; Wang et al. 2000). These circulations significantly affect the structure of the Planetary Boundary Layer (PBL), the heat and moisture fluxes (Li and Avissar 1994; Chen and Avissar 1994a; Lynn et al. 1995; Dalu et al. 1996), and the cloud and precipitation organization (Chen and Avissar 1994b; Wetzel et al. 1996; Wang et al. 2000). As the exchange of energy, moisture, and momentum between the land surface and the atmosphere are important components of the climate system, the occurrence of changes in these fluxes, resulting from mesoescale circulations caused by natural or humaninduced heterogeneity, can potentially influence heat exchange and moisture circulation at the GCM scale. Using a regional climate model (Eta model) coupled with the Simplified Simple Biosphere Model-SSiB (Xue et al. 1991), nested to the general circulation model from the Brazilian Center for Weather Forecasting and Climate Studies (GCM/CPTEC), this study evaluates how land cover changes (deforestation scenarios for current and potential future conditions) in Amazônia affect the regional climate.

\section{Model description}

\subsection{ETA regional model}

The main features of the Eta regional model are described in Black (1994) and Chou et al. (2002). 
The National Center for Environmental Prediction's (NCEP) ETA model is an operational shortrange forecasting model used over the North and South American regions (Mesinger et al. 1988). The Eta model domain is positioned within about $57^{\circ} \mathrm{S}-13^{\circ} \mathrm{N}$ and about $100^{\circ} \mathrm{W}-20^{\circ} \mathrm{W}$, centered at $22^{\circ} \mathrm{S}, 60^{\circ} \mathrm{W}$. One of the features of this model is the vertical coordinate $\eta$ (Mesinger 1984). This coordinate has relatively horizontal surfaces at all times and orography is represented by steplike functions. With this system, well-known errors associated with determining the pressure gradient force along a steeply sloped coordinate surface are minimized. The $\eta$ coordinate becomes appropriate for simulations over South America because the Andes Cordillera has very steep slopes along most of its longitudinal exension. Finite difference schemes are applied to the model system of equations in space and time. The discretization of the domain is done with the semi-staggered Arakawa E-grid in the horizontal, and the Lorenz grid in the vertical. The following numerical methods are used in the model: (i) a horizontal advection scheme developed by Janjic (1984) that conserves momentum and energy and restricts the cascade of energy toward the smaller scales; (ii) a second order nonlinear lateral diffusion based on the turbulent kinetic energy; (iii) a forward-backward scheme for the inertia-gravity wave, modified according to Mesinger (1977) and Janjic (1979) to prevent gravity wave separation; and (iv) a split-explicit time differencing with a time step of $200 \mathrm{sec}$ for the inertia-gravity wave. The resolution used in the Eta model is $40 \mathrm{~km}$ horizontally and 38 vertical layers, with higher resolution in the boundary layer and in the upper troposphere/lower stratosphere. The Egrid is configured on a rotated latitude-longitude grid, in which the center of the grid lies at the center of the integration domain.

The physics of the model contains: (a) a modified Betts-Miller cumulus parameterization (Betts and Miller 1986), which is also used for shallow convection; (b) a Mellor-Yamada level 2.5 scheme to account for turbulence between the model layers inside the boundary layer and in the free atmosphere; and (c) a Mellor-Yamada level 2.0 scheme to account for turbulence between the ocean surface and the lowest model layer. In the Mellor-Yamada schemes, the turbulent kinetic energy is calculated at model layer interfaces and is used to compute the exchange coefficients for the transfer of heat, moisture and momentum. The radiation package uses the schemes of Lacis and Hansen (1974) and Fels and Schwarztkopf (1975) for the shortwave and the longwave radiations, respectively. Both stratiform and cumuliform interactive clouds are diagnosed (Slingo 1987) based on the model's relative humidity and convective rainfall rate. The surface fluxes of momentum, sensible heat, latent heat and radiation over land are nonlinearly determined by the interaction between the lowest model layer and the surface using the Simplified Simple Biosphere Model - SSiB (Xue et al. 1991). Over ocean areas, the surface fluxes are determined using Monin-Obukhov theory according to Lobocki (1993). Boundary conditions for the Eta model include sea surface temperature, orography and vegetation land cover.

\subsection{SSiB model}

The SSiB is a simplified version by Xue et al. (1991) of the Simple Biosphere Model (SiB) proposed by Sellers et al. (1986). It includes 12 different vegetation types according to Dorman and Sellers (1989), and it is set up with three soil layers and one canopy layer. The main land cover groups in South America are broadleaf evergreen (Tropical forest), mixed broadleaf deciduous, grass and broadleaf deciduous shrubs (savanna), and broadleaf deciduous shrubs (caatinga). The SSiB model has eight prognostic variables: soil wetness for three layers; temperature at the canopy, ground surface, and deep soil layers; snow depth at the ground; and water intercepted by the canopy. An implicit backwards scheme is used to calculate the temperature tendency in the coupling of the lowest atmospheric model layer with the SSiB model, such that the energy conservation between the land surface and the atmosphere is satisfied. The soil temperature is calculated by the force-restore method, and the water movement in the soil is described with a diffusion equation. Each vegetation type has a set of parameters to describe the plant physiology. From the atmospheric model Eta, SSiB receives temperature, vapor pressure, and wind speed at the lowest sigma level of the model as well as short wave and long wave radiation fluxes and precipitation at the surface. The SSiB communicates back to 
F. W. S. Correia et al.

Table 1. Biophysical parameters of the Simple Biosphere Model ( $\mathrm{SiB}$ ) for tropical forest, cerrado and pasture vegetation types

\begin{tabular}{lccc}
\hline Parameter & Tropical forest & Cerrado* & Pasture \\
\hline Leaf area index $-\mathrm{LAI}\left(\mathrm{m}^{2} \mathrm{~m}^{-2}\right)$ & $4.82^{(1)}$ & $2.60^{(3)}$ & $1.53^{(1)}$ \\
Roughness length $-\mathrm{z}_{0}(\mathrm{~m})$ & $2.55^{(1)}$ & 0.97 & $0.02^{(1)}$ \\
Zero plane displacement $-d(\mathrm{~m})$ & $29.10^{(1)}$ & $14.60^{(3)}$ & $0.20^{(1)}$ \\
Fractional area covered by vegetation $-\mathrm{V}_{\mathrm{c}}$ & $0.93^{(1)}$ & 0.30 & $0.74^{(1)}$ \\
Canopy height $(\mathrm{m})$ & $35.0^{(2)}$ & 18.0 & $0.6^{(2)}$ \\
Root depth $(\mathrm{m})$ & 3.00 & 0.50 & 0.60 \\
Soil moisture potential parameter $-B\left(\mathrm{~m} \mathrm{~s}^{-1}\right)$ & 7.12 & 7.12 & 10.40 \\
Porosity $-\theta_{s}\left(\mathrm{~m}^{3} \mathrm{~m}^{-3}\right)$ & $0.48^{(1)}$ & 0.42 & $0.49^{(1)}$ \\
Saturated hydraulic conductivity $-K_{s}\left(\mathrm{~m} \mathrm{~s}^{-1}\right)$ & $4.6 \times 10^{-6(1)}$ & $0.2 \times 10^{-4}$ & $1.5 \times 10^{-5(1)}$ \\
Leaf water potential parameters: & & & $1.80^{(4)}$ \\
$\Psi_{1}(\mathrm{~m})$ & $1.19^{(1)}$ & $5.67^{(4)}$ & $1.85^{(1)}$ \\
$\Psi_{2}(\mathrm{~m})$ & $6.27^{(1)}$ & $5.77^{(1)}$ \\
\hline
\end{tabular}

* Savanna-like vegetation.

Superscripts refer to the source references as follows: ${ }^{(1)}$ Correia et al. (2005); ${ }^{(2)}$ Nobre et al. (1991); ${ }^{(3)}$ Dorman and Sellers (1989); ${ }^{(4)}$ Xue et al. (1991)

the Eta model through the sensible and latent heat fluxes and the momentum flux. The fluxes in $\mathrm{SSiB}$ are determined as a ratio of potential difference to resistance. There are three aerodynamic resistances corresponding to the resistance between the soil surface and canopy air space; the resistance between canopy leaves and canopy air space; and the resistance between canopy air space and reference height. These resistances are obtained as a function of the morphology of vegetation, the soil type, the wind speed and the corresponding potential difference of temperature. Many parameters have been calibrated using measurements taken on forest and pasture sites in the Amazon region (Correia et al. 2005), as shown in Table 1.

\section{Experiment design and deforestation scenarios}

\subsection{Numerical integrations}

Four simulation runs were performed, hereafter referred to as CONTROL, PROVEG, CEN2033 and DESFLOR. In the CONTROL and PROVEG experiments, the South American vegetation map includes land cover representations of Legal Amazon with (PROVEG) and without (CONTROL) deforested areas, as elaborated by the ProVeg Project (Sestini et al. 2002) from the base year 1997 (Fig. 1). The region presents a great variety of vegetation types and, in order to simplify, the different types of vegetation were classified to $\mathrm{SSiB}$ types as forest, pasture and cerrado (a type
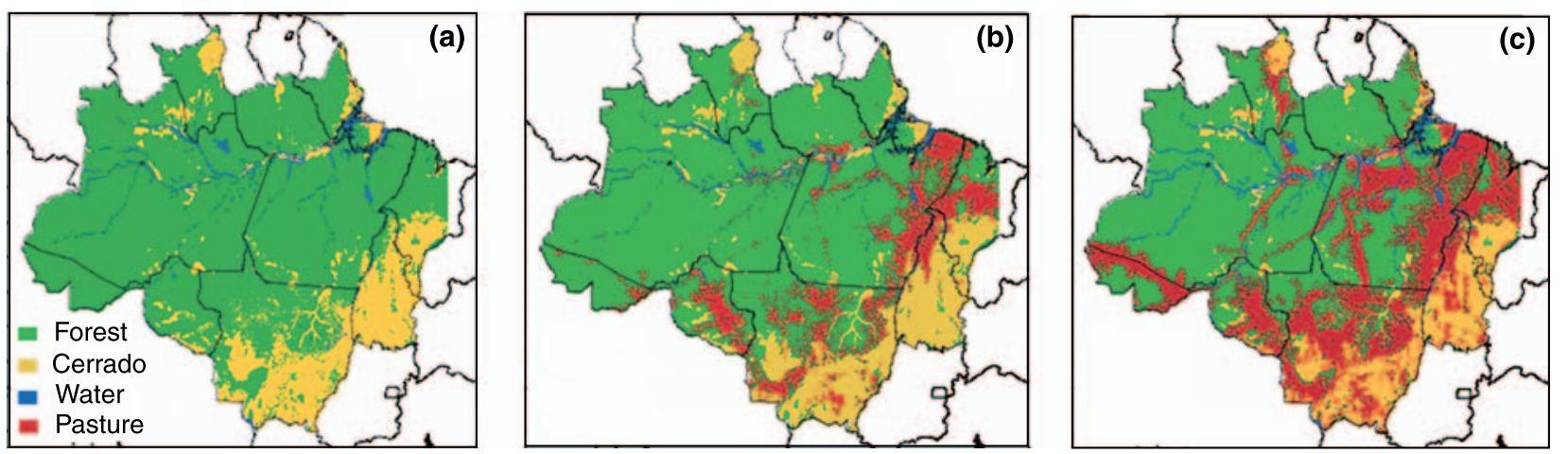

Fig. 1. Deforestation scenarios with a horizontal resolution of $1 \mathrm{~km} \times 1 \mathrm{~km}$. (a) no deforestation scenario used for the CONTROL simulation; (b) current deforestation scenario produced by the ProVeg Project (Sestini et al. 2002) and used in the PROVEG simulation; (c) deforestation scenario for 2033 used in the CEN2033 simulation. On the map, green means tropical forest; yellow, cerrado (a type of savanna); blue, water, and red, degraded pasture 
of savanna). In the CEN2033 experiment, a deforestation scenario for year 2033 was developed using a landscape dynamics model (Soares-Filho et al. 2004). Finally, the DESFLOR experiment assumed that all of Amazonia's tropical forest area was replaced by degraded pasture, similar to what has been done in other Amazonia deforestation impact studies (Hahmann and Dickinson 1997). The CPTEC/GCM T62L28 simulations were used for initial and lateral boundary conditions. The latter were updated every $6 \mathrm{~h}$. The Eta model was integrated for a 13 -month period, starting at 0000 UTC on December 1, 1999. The first month of model spin-up time was excluded; the results shown and discussed here refer to the last twelve months. The initial conditions for the horizontally non-homogeneous soil moisture content were derived from CPTEC/GCM. Climatological sea surface temperature (SST) was used in all experiments. Except for the landcover changes, all other initial and prescribed boundary conditions were kept identical in all simulations. The standard Student's $t$-test was used to assess significance, assuming independent values at each grid point and with monthly mean values taken as independent samples.

\subsection{Current deforestation scenario - PROVEG}

The vegetation map, which included the current deforestation in Amazônia (PROVEG), was provided by the ProVeg Project, lead by INPE (Sestini et al. 2002). This map was generated using RADAMBRASIL Project data, at a 1:1,000,000 scale, and Instituto Brasileiro de Geografia e Estatística (IBGE, Brazilian Geography and Statistics Institute) vegetation land cover data, at a 1:5,000,000 scale (IBGE 1993), both available in digital format. Deforestation assessments conducted by the Project for Monitoring the Brazilian Amazon Gross Deforestation (INPE 2004) have been used to include the anthropogenic land cover changes that have been occurring in Amazonia over the last several years (Fig. 1b). The assessments were based on Landsat Thematic Mapper (TM) satellite imagery analysis, of 112 scenes over the arc of deforestation (a region of intensive deforestation in the Legal Amazon) for base year 1997. The vegetation maps from IBGE and the RADAM project contain "contact" areas, which occur when two or three different vegeta- tion types combine. Since the SSiB model does not recognizes these contact vegetation types, the ProVeg Project used a Landsat TM mosaic from 2000 to determine the contact areas and generate a more realistic land cover scenario, compatible with the $\mathrm{SSiB}$ biomes.

\subsection{Future deforestation scenario - CEN2033}

The Amazonian deforestation scenario for year 2033 was obtained using the DINAMICA landscape dynamics model (Soares-Filho et al. 2002, 2004). It is a cellular automata model that presents multi-scale vicinity-based transitional functions, incorporating a spatial feedback approach to a stochastic multi-step simulation engine, and applies logical regression to calculate the spatial dynamics transitions probabilities. This model was initially designed to simulate the landscape dynamics in an Amazonian colonization frontier, particularly landscapes that evolve in farm-occupied areas. DINAMICA uses landscape maps as its main input (e.g., a land-use and land-cover map obtained by digital classification of remote sensing images). Also as input, the model employs selected spatial variables, which are structured in two cartographic subsets according to their dynamic or static nature. The road construction model can be coupled to the DINAMICA model, allowing for the incorporation of dynamic highway network maps. Figure 1c shows the deforestation map for 2033.

\section{Control simulation}

To evaluate the model's performance, we used average precipitation data compiled by Janowiak and Xie (1999) for January and June 2000, and data from ground stations obtained by the following Brazilian institutes: National Space Research Institute's Data Collection Mission Center (CMCD/INPE), National Meteorological Institute (INMET), Meteorology, Hydrological Resources and Remote Sensing Laboratory of Paraíba (LMRS/PB), Ceará's Meteorological Foundation (FUNCEME), Agriculture Research Institute of Rio Grande do Norte (EMPARN/RN), Department of Meteorology and Hydrological Resources of the State of Pernambuco (DMRH/ PE), Hydrometeorology Department of the State of Piauí (DHME/PI), Mineral Resources and In- 
F. W. S. Correia et al.

dustrial Development Company of Sergipe (CEPES/SE), Meteorology and Water Resources Nucleus of the State of Alagoas (NMRH/AL), State of Bahia Secretary for Water Resources (SRH/BA), Power Company of Minas Gerais (CEMIG/SIMGE/MG), State of Espírito Santo Secretary for Agriculture (SEAG/ES), Meteoro-
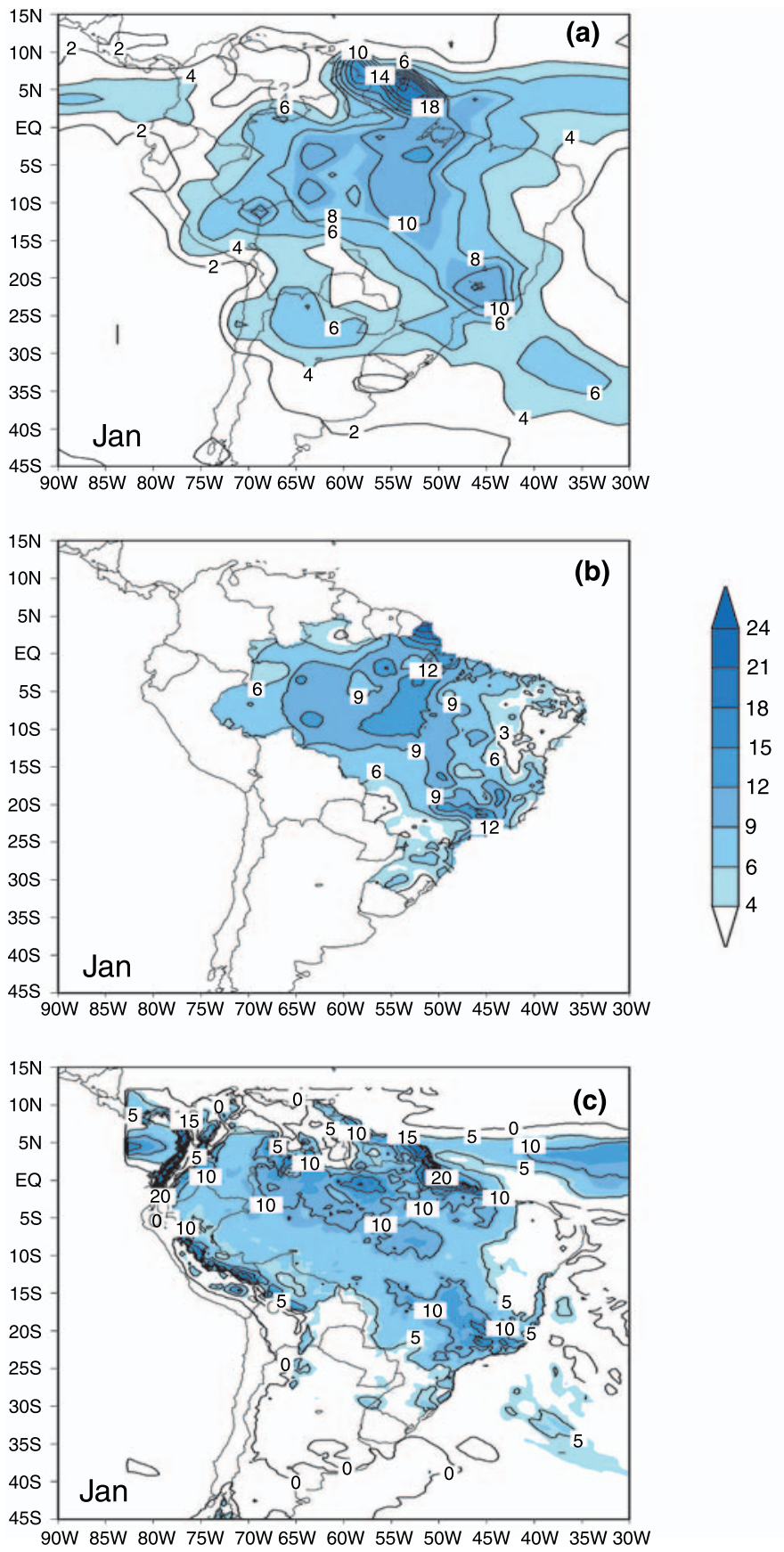

logical System of Paraná (SIMEPAR/PR) and Integrated Center for Meteorology and Water Resources of Santa Catarina (CLIMERH/SC).

The data observed show a region of highly localized precipitation extending from the Southeast to the extreme north of the continent, as shown in Fig. 2a and b. The high precipitation
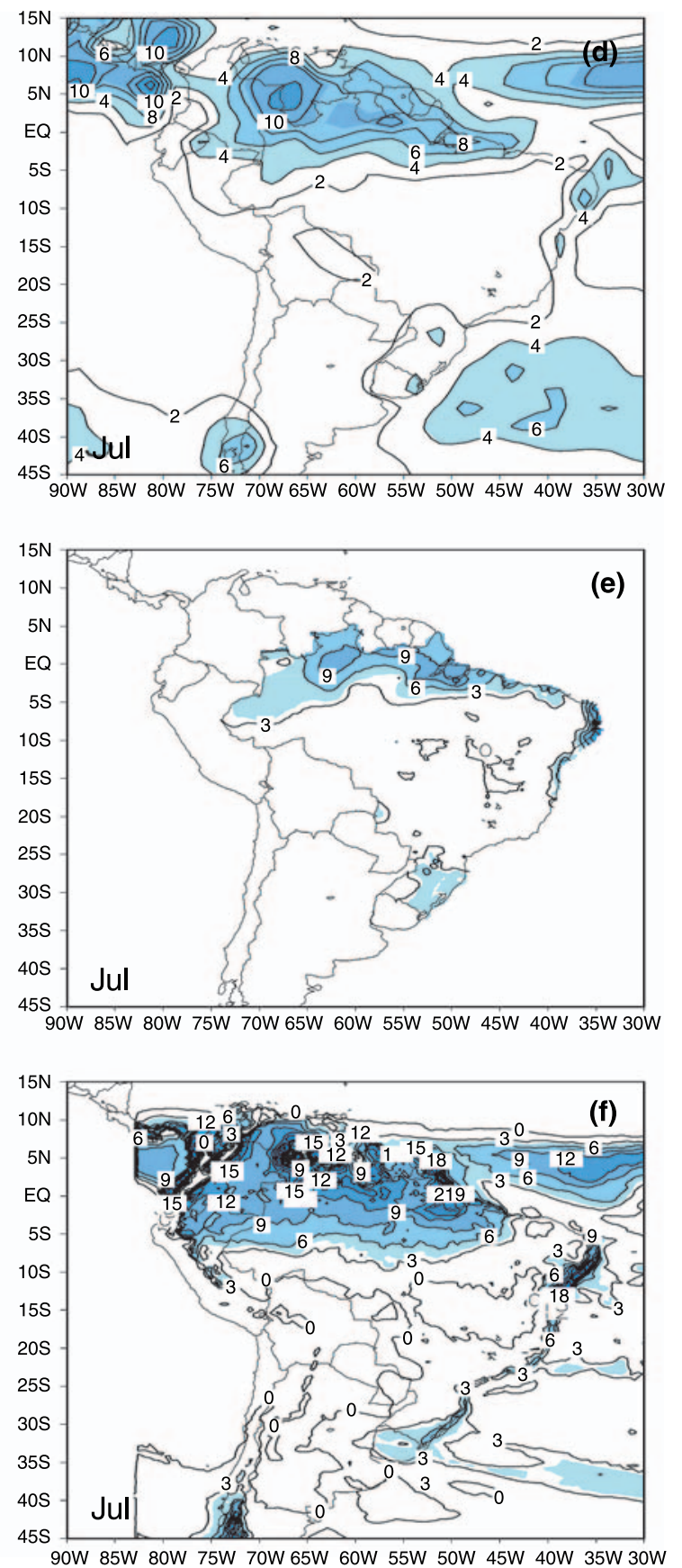

Fig. 2. Spatial patterns of observed and modeled precipitation $\left(\mathrm{mm} \mathrm{day}^{-1}\right)$ for January and July for South America: (a, b) For January, observations from Janowiak and Xie (1999) and ground stations data from several Brazilian Institutes, respectively; (c) predictions of the control simulation for January; (d, e) For July, observations from Janowiak and Xie (1999) and ground stations data from several Brazilian Institutes, respectively; (f) predictions of the control simulation for July 
line coincides with the average position of the South Atlantic Convergence Zone (SACZ), being associated with low altitude moisture convergence and intensified by frontal systems that move towards the equator. The values of the rain distribution over land estimated by the regional model for the humid month were similar to the ones observed in the central part of the continent (Fig. 2c). The model produced intense precipitation over the Southeast, which was also verified in Janowiak and Xie's (1999) data, as well as in the data from the field stations. The high precipitation region near to the state of Amapá, approximately $5^{\circ} \mathrm{N}$ and $55^{\circ} \mathrm{W}$, observed in the Janowiak e Xie (1999) data also was well simulated by the model. The Intertropical Convergence Zone (ITCZ) over the Atlantic and Pacific Oceans was correctly positioned. The precipitation band over the Atlantic Ocean, between $25^{\circ} \mathrm{S}$ and $40^{\circ} \mathrm{S}$, was also correctly positioned, with values consistent with the ones observed. Over the Amazonia region, the model successfully simulated the precipitation distribution, with values of the order of $10 \mathrm{~mm} \mathrm{day}^{-1}$; however, over the northeast region, the precipitation was underestimated by up to $3 \mathrm{~mm} \mathrm{day}^{-1}$.

During the dry month (July), the precipitation observed over the continent took place in three regions: the extreme north of South America, the eastern coast of the Northeast, and southern Brazil (Fig. 2d). Different climate regimes are responsible for the precipitation patterns in these different regions. In general, the model was able to show the spatial distribution of rain maxima over the continent during this period. In terms of order of magnitude, the regional model best represented the maximum precipitation region in the north of the continent; however, it produced excessive rain near the northern part of the Andes (Fig. 2f). This systematic precipitation error is due to the topographical effect, also observed by Chou et al. (2002). The positioning of the ITCZ and the cloud band over the Atlantic Ocean were well simulated; however, the model overestimated the precipitation over this convergence zone and also over the eastern part of the Northeast's coast.

\section{Regional climate changes}

This section presents the results of the simulations using the PROVEG, CEN2033 and DES-
FLOR deforestation scenarios; their impacts on the regional climate are evaluated by the differences between them and the CONTROL simulation. The statistical significance of the anomalies is evaluated using the Student $t$-test with confidence level of $99 \%$. The climatic impacts that these scenarios have on the annual averages of precipitation, evapotranspiration and moisture convergence are here assessed. For the PROVEG scenario, the precipitation presented a small increase of $0.9 \mathrm{~mm}$ day $^{-1}$ near the deforested area of eastern Pará, with statistical significance at $99 \%$ (Fig. 3a). No reduction in the regional precipitation was detected for the PROVEG scenario. This precipitation increase, located in the State of Pará, is related to a significant increase in the moisture convergence of the order of $1.0 \mathrm{~mm} \mathrm{day}{ }^{-1}$ (statistical significance at 99\%), since the evapotranspiration was reduced over the deforested region (Figs. 4a and 5a). This result could indicate that the deforestation, as simulated by PROVEG, contributed to the modifications in the dynamic atmospheric structure and, consequently, created meso-scale circulation as a result of differential heating related to the heterogeneity of the surface, once the thermal and radiative characteristics of the vegetation cover were modified. This result is consistent with the experimental evidence (from satellite observation analyses) of the increase of the cloud cover and precipitation over deforested areas of Amazonia provided by Durieux et al. (2003). Examining the climate effects of changes in the vegetation cover over the arc of deforestation, Durieux et al. (2003) observed that during the dry season there were more low clouds present in the afternoon, while during the rainy season, the convection was stronger over pasture during the night, leading to an increase in local precipitation. Even though there was an increase in direct soil evaporation, the decrease in the transpiration and the evaporation of water intercepted by plants was sufficient to result in a reduction of the evapotranspiration over the deforested area. Other studies using high resolution regional models have demonstrated that the differential heating of the Planetary Boundary Layer (PBL), due to surface heterogeneity, creates a horizontal gradient in the latent and the sensible heat turbulent fluxes, which may generate intense mesoscale circulations (Silva Dias and Regnier 1996; 
F. W. S. Correia et al.
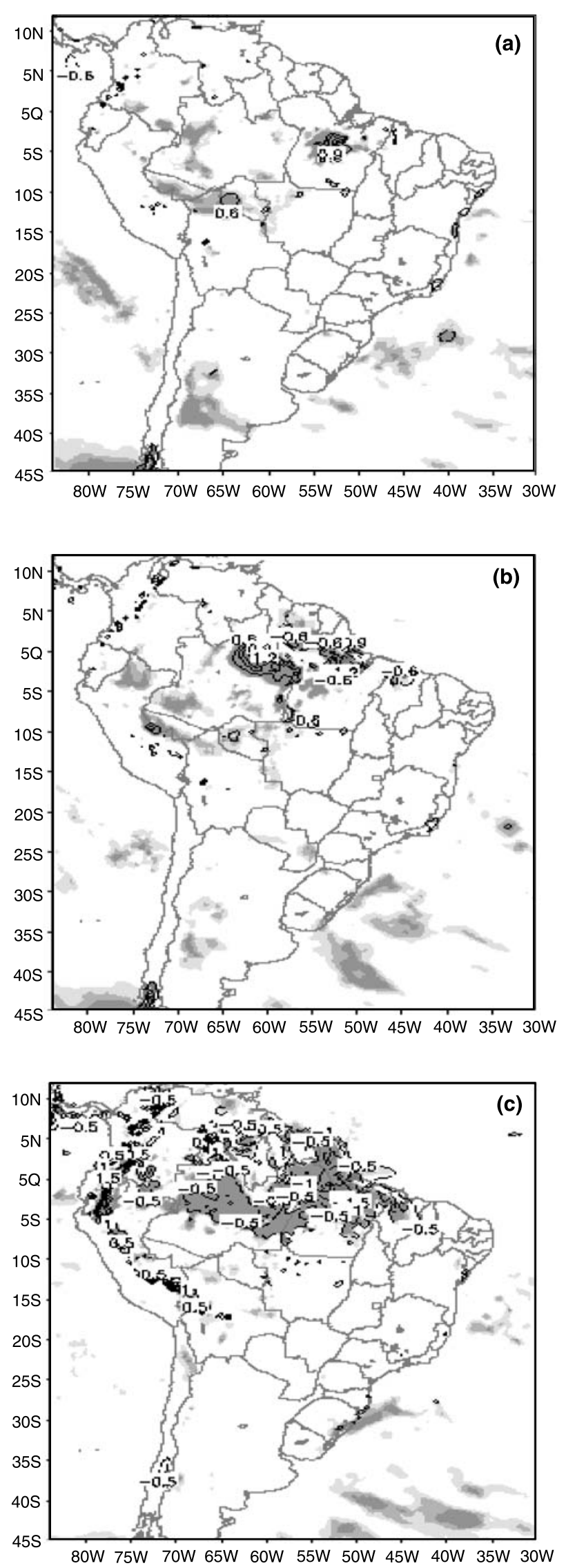

Avissar and Schmidt 1998; Wang et al. 2000; Weaver and Avissar 2002). Silva Dias and Regnier (1996) observed the presence of mesoscale circulations in response to differential surface heating in the transition area between Amazonian forests and pastures. These circulations were the result of complex interactions among the different types of vegetation, the topography and the large-scale drainage.

With the CEN2033 deforestation scenario an increase in precipitation was observed in the central-east Amazonia ( $\left.1.2 \mathrm{~mm} \mathrm{day}^{-1}\right)$, as shown in Fig. 3b. Significant reductions were also observed in several localized areas, primarily in the north and the northeast of the Amazon Basin. The increase of precipitation in this same region can be explained, with high statistical significance, by the local increase in moisture convergence. In northern Amazonia, the reduction in precipitation was related to a reduction in evapotranspiration, while the increase in precipitation was due to mesoscale circulation changes which favored moisture transport to that region (Figs. 4b and 5b). These results (increases and decreases in different locations) may indicate that the CEN2033 deforestation scenario produced local/regional changes in the atmospheric circulation and, consequently, in the local convergence of moisture. The annual mean precipitation increased over the deforested region, which was also the result of increased local moisture convergence, despite an observed reduction in evapotranspiration. Evaluating the tri-dimensional structure and the evolution of convective clouds with a mesoscale atmospheric model, Avissar and Liu (1996) observed that the cloud and precipitation distribution is strongly affected by the landscape structure; also, the mesoscale circulation's upward movement generated by the heterogeneous surface is stronger than the thermal cells induced by the turbulence. In addition to this, the ability of this meso-scale circulation to carry hot and humid air to high atmospheric levels increases the quantity of water that can

Fig. 3. Modeled annual mean differences of precipitation $\left(\mathrm{mm} \mathrm{day}{ }^{-1}\right)$ : (a) PROVEG-CONTROL; (b) CEN2033CONTROL; (c) DESFLOR-CONTROL. Student's fields showing changes that are locally significant at the $99 \%$ confidence level. Solid (dashed) lines represent positive (negative) anomalies 
Modeling the impacts of land cover change in Amazonia
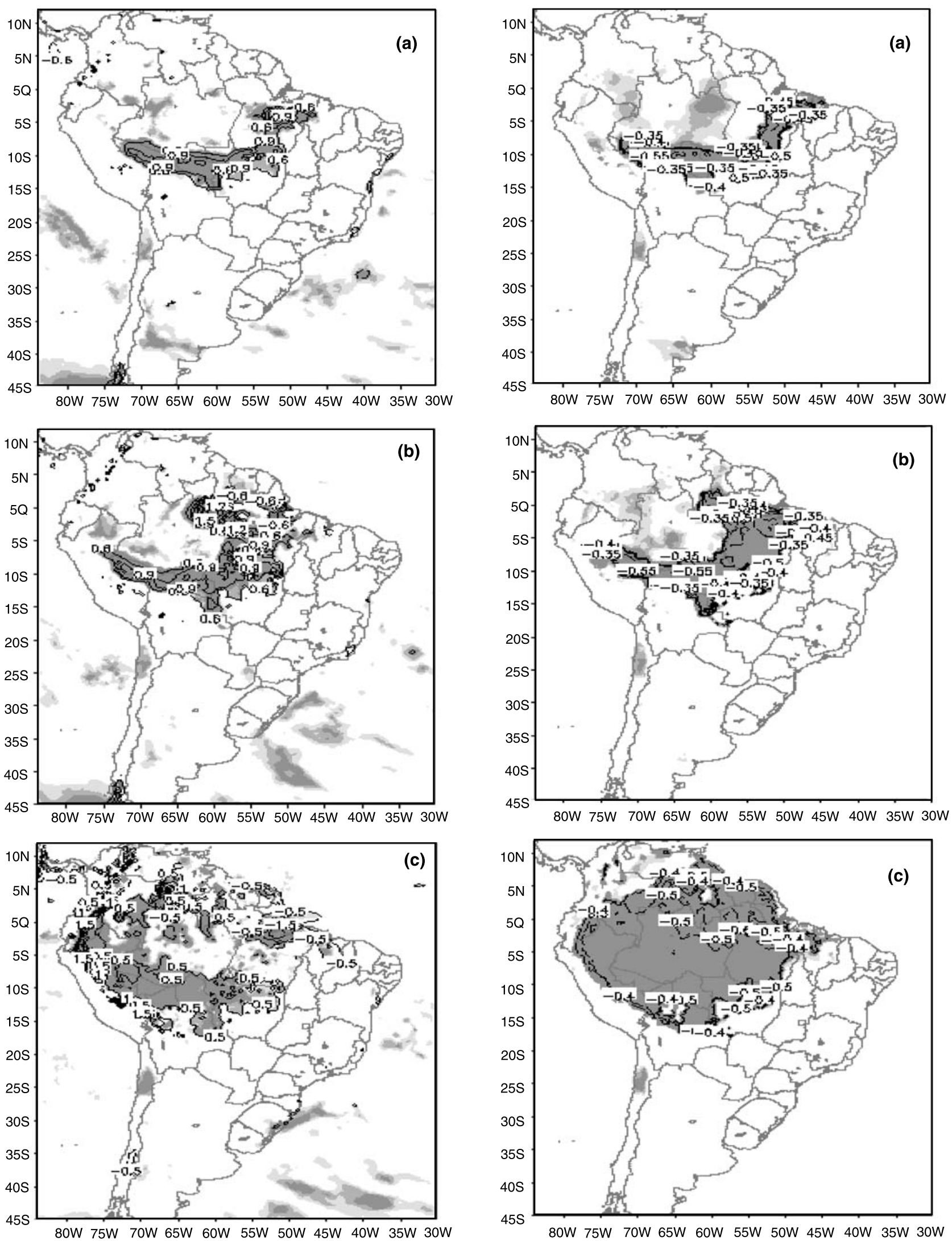

Fig. 4. Modeled annual mean differences of moisture convergence $\left(\mathrm{mm} \mathrm{day}^{-1}\right)$, with the same comparisons as on Fig. 3

Fig. 5. Modeled annual mean differences of evapotranspiration $\left(\mathrm{mm} \mathrm{day}^{-1}\right)$, with the same comparisons as on Fig. 3 
F. W. S. Correia et al.

be condensed and, consequently, be precipitated (Wang et al. 2000).

Different from previous simulations, an increased precipitation was not observed with the DESFLOR scenario; however, significant reductions are notable in the east and northeast of the Legal Amazonia (Fig. 3c). A significant increase was observed in the extreme western part of the South American continent, resulting from the increase in moisture convergence over this region (Fig. 4c). On average, the precipitation decreased $12 \%$ and the evapotranspiration decreased $32 \%$ over the deforested area, demonstrating that there is an increase in moisture convergence over deforested areas. Despite this, the increase in moisture convergence was not intense enough to balance and overcome the reduced evapotranspiration, which resulted in a precipitation deficit over the region. The large-scale deforestation scenario contributed to the regional circulation changes, creating circulations that favor regional moisture convergence and are related to the increased surface heating and the changes in vegetation cover characteristics. These results confirm the ones observed in both the PROVEG and the CEN2033 experiments, that is, the atmosphere reacted to minimize the effects of reduced evaporation; however, contrary to what was observed in the previous simulations, the significantly reduced evapotranspiration over the region led to a reduced precipitation (Fig. 4c). Different results, particularly the reduction of the moisture convergence, were obtained in other deforestation simulations, such as the ones by Polcher and Laval (1994), McGuffie et al. (1995), Hahmann and Dickinson (1997), Costa and Foley (2000), and Voldoire and Royer (2004). Using a high resolution atmospheric regional model to evaluate deforestation effects in the western Amazon Basin, Gandu et al. (2004) observed a reduction of precipitation and cloud cover over the coast of Amapá, the eastern part of Marajó Island, and along the large rivers in this region; also, increased precipitation and cloud cover were observed in the mountain regions of south-central Pará State and the northern part of the State of Amazonas.

\section{Energy and radiation budget}

To evaluate the impact of land cover changes on the energy and radiation budget for each of the scenarios, the changes in three important variables were evaluated: albedo, temperature and cloudiness. The increase in albedo varied from 0.13 over forest areas to 0.19 over pasture areas (Table 2). An increase in surface temperature was observed in all of the scenarios, with annual mean values ranging from 2.0 to $2.8^{\circ} \mathrm{C}$ and with the most significant temperature impacts observed during the dry season, when the evapotranspiration was limited by the available soil moisture. A reduced surface net radiation was observed in all scenarios (of 24.4, 25.7, and $27.8 \mathrm{~W} \mathrm{~m}^{-2}$ for the PROVEG, CEN2033 and DESFLOR scenarios, respectively). With the PROVEG scenario, the reduction of the incoming short wave radiation, resulting from increased cloudiness, contributed to a reduction in the surface net radiation; thus, the surface short wave radiation budget decreased of -18.3 and $-14.2 \mathrm{~W} \mathrm{~m}^{-2}$ in the wet and dry seasons, respectively. The cloud mechanism, in which the increase in surface reflected solar radiation is balanced by an increase in incoming solar radiation, was not observed in any of the scenarios. In general, the increase in albedo was primarily responsible for the reduced radiation balance, since the loss of surface long wave radiation had less influence in this scenario (Fig. 6). Similarly, with the CEN2033 scenario there was a reduction in incoming short wave radiation due to the local increase in cloudiness, and a decrease in the surface net radiation due to increased albedo. These two factors led to a decrease in the surface short wave radiation budget in both wet and dry seasons. With the large-scale deforestation scenario (DESFLOR), an increase in incoming solar radiation was observed, resulting from reduced cloudiness in the middle and the upper atmosphere; finally, different from the other scenarios, the long wave radiation loss was more important for the surface net radiation decrease than for the albedo increase.

Concerning the long wave radiation, the increase of outgoing radiation in the CEN2033 scenario, resulting from increased surface temperature, played a dominant role in reducing the surface long wave budget, since there were practically no changes in the incoming radiation. The incoming long wave radiation increased and decreased in both PROVEG and DESFLOR scenarios, respectively, and was related to the cloud 
Modeling the impacts of land cover change in Amazonia

Table 2. Annually averaged absolute changes of the surface climate parameters for PROVEG, CEN2033 and DESFLOR scenarios

\begin{tabular}{|c|c|c|c|c|c|c|c|c|c|}
\hline \multirow[t]{2}{*}{ Climate parameter } & \multicolumn{3}{|c|}{ PROVEG } & \multicolumn{3}{|c|}{ CEN2033 } & \multicolumn{3}{|c|}{ DESFLOR } \\
\hline & Annual & wet* & dry* & Annual & wet & dry & Annual & wet & dry \\
\hline$S W_{s f c} \downarrow$ & -4.3 & -4.8 & +0.4 & -2.5 & -1.4 & -1.6 & +5.4 & +4.9 & +3.0 \\
\hline$S W_{s f c} \uparrow$ & +14.0 & +13.5 & +14.6 & +14.4 & +14.2 & +13.7 & +15.6 & +15.8 & +14.2 \\
\hline$\Delta S W_{s f c}$ & -18.3 & -18.3 & -14.2 & -16.9 & -15.6 & -15.3 & -10.2 & -10.9 & -11.2 \\
\hline$L W_{s f c} \downarrow$ & +3.0 & +1.9 & +0.7 & +0.2 & -0.2 & -0.8 & -2.7 & -1.1 & -3.4 \\
\hline$L W_{s f c} \uparrow$ & +9.1 & +8.9 & +13.6 & +9.0 & +8.6 & +11.5 & +14.9 & +9.2 & +14.0 \\
\hline$\Delta L W_{s f c}$ & -6.1 & -7.0 & -12.9 & -8.8 & -8.8 & -12.3 & -17.6 & -10.3 & -17.4 \\
\hline$R N_{s f c}$ & -24.4 & -25.3 & -27.1 & -25.7 & -24.4 & -27.6 & -27.8 & -21.2 & -28.6 \\
\hline$\alpha$ & +0.06 & +0.06 & +0.06 & +0.06 & +0.06 & +0.06 & +0.06 & +0.06 & +0.06 \\
\hline$N$ & +4.9 & +5.9 & +2.6 & +3.9 & +3.9 & +4.2 & +1.7 & +1.4 & +3.6 \\
\hline$T_{S}$ & +2.0 & +1.7 & +1.9 & +2.4 & +1.8 & +2.2 & +2.8 & +2.1 & +2.6 \\
\hline$H$ & -0.9 & -2.0 & +1.8 & +2.8 & -0.5 & +2.0 & +7.0 & +3.4 & +4.9 \\
\hline$L E$ & -24.6 & -23.8 & -30.4 & -28.7 & -24.0 & -30.9 & -31.6 & -24.3 & -33.1 \\
\hline$G$ & +1.1 & +0.5 & +0.3 & +0.7 & +0.3 & +1.1 & +0.8 & +0.2 & +1.0 \\
\hline$B_{o}$ & +0.05 & +0.03 & +0.08 & +0.09 & +0.04 & +0.11 & +0.15 & +0.08 & +0.16 \\
\hline$P_{s f c}$ & -0.4 & -0.1 & -0.2 & -0.5 & -0.1 & -0.5 & -0.9 & -0.3 & -0.3 \\
\hline$U_{s f c}$ & +0.4 & +0.3 & +0.6 & +0.5 & +0.5 & +0.7 & +0.9 & +0.7 & +0.9 \\
\hline$P$ & +0.66 & +0.65 & -0.04 & +0.39 & +0.42 & +0.03 & -0.63 & -0.57 & -0.70 \\
\hline$E P$ & -0.39 & -0.31 & -0.41 & -0.56 & -0.47 & -0.60 & -1.40 & -1.04 & -1.23 \\
\hline$E T$ & -0.56 & -0.47 & -0.31 & -0.63 & -0.72 & -0.30 & -1.28 & -0.91 & -1.15 \\
\hline$R$ & +1.03 & +4.3 & +0.6 & +1.05 & +4.9 & +0.6 & +0.75 & +4.82 & +1.14 \\
\hline
\end{tabular}

$S W_{s f c} \downarrow, S W_{s f c} \uparrow$, and $\Delta S W_{s f c}$ : Solar downward, solar upward and net solar fluxes $\left(\mathrm{W} \mathrm{m}^{-2}\right)$, respectively; $L W_{s f c} \downarrow, L W_{s f c} \uparrow$ and $\Delta L W_{s f c}$ : long-wave downward, long-wave upward and net long wave fluxes $\left(\mathrm{W} \mathrm{m}^{-2}\right)$, respectively; $R N_{s f c}$ surface net radiation $\left(\mathrm{W} \mathrm{m}^{-2}\right) ; \alpha$ albedo (dimensionless); $n$ cloudiness $(\%) ; T_{S}$ surface temperature $\left({ }^{\circ} \mathrm{C}\right) ; H$ sensible heat flux $\left(\mathrm{W} \mathrm{m}^{-2}\right) ; L E$ latent heat flux $\left(\mathrm{W} \mathrm{m}^{-2}\right) ; G$ soil heat flux $\left(\mathrm{W} \mathrm{m}^{-2}\right) ; B_{o}$ Bowen ratio (dimensionless); $P_{s f c}$ surface pressure $(\mathrm{hPa}) ; U_{s f c}$ wind surface $\left(\mathrm{m} \mathrm{s}^{-1}\right)$; $P$ precipitation $\left(\mathrm{mm} \mathrm{day}^{-1}\right) ; E P$ evapotranspiration $\left(\mathrm{mm} \mathrm{day}^{-1}\right) ; E T$ transpiration $\left(\mathrm{mm} \mathrm{day}{ }^{-1}\right) ; R$ runoff $\left(\mathrm{mm} \mathrm{day}^{-1}\right)$

* Wet and dry seasons

cover in each of the scenarios. The long and the short wave radiation budgets contributed to a reduced surface net radiation, with the second one presenting a greater contribution in both PROVEG and CEN2033 scenarios. The impacts on the radiation budget are more significant during the dry season; for example, the increase in outgoing long wave radiation is more intense and, therefore, changes in the surface net radiation are also more intense. This result corroborates the ones from other deforestation experiments implemented with GCMs, in which more significant changes were observed in the dry season, due to the soil moisture deficit (Sud et al. 1996a; Hahmann and Dickinson 1997; Lean and Rowntree 1997). Nobre et al. (1991) observed that the reduced net radiation is governed by the increase in albedo, leading to a decrease in the short wave surface radiation budget, while Manzi and Planton (1996) and Hahmann and Dickinson (1997) observed an increase in incoming short wave surface radiation caused by the decrease in cloud cover, which cancelled the albedo increase effect (cloud mechanism). These divergent results among the simulations demonstrate their strong dependence on the cloud and the radiative transfer parameterizations.

Changes in cloudiness vary in each of the scenarios considered. An increased lower troposphere cloud cover was observed in all of the scenarios, but with a reduction in the middle and high troposphere cloud cover in the DESFLOR scenario (Fig. 6). For the PROVEG scenario, the cloudiness at low levels increased by an annual mean of $4.9 \%$, varying from $5.9 \%$ to $2.6 \%$ during the wet and dry season, respectively, while for the CEN2033 scenario the cloudiness increased $3.9 \%(4.2 \%)$ in the wet (dry) season. Observational evidence for the increase of the cloud cover, over or near deforested areas in Amazonia, was also provided by $\mathrm{Chu}$ et al. (1994), Cutrim et al. (1995), Durieux et al. (2003), Negri and Adler (2004), and Chagnon et al. (2004). Using satellite information, Cutrim et al. (1995) showed that deforestation can lead 
F. W. S. Correia et al.
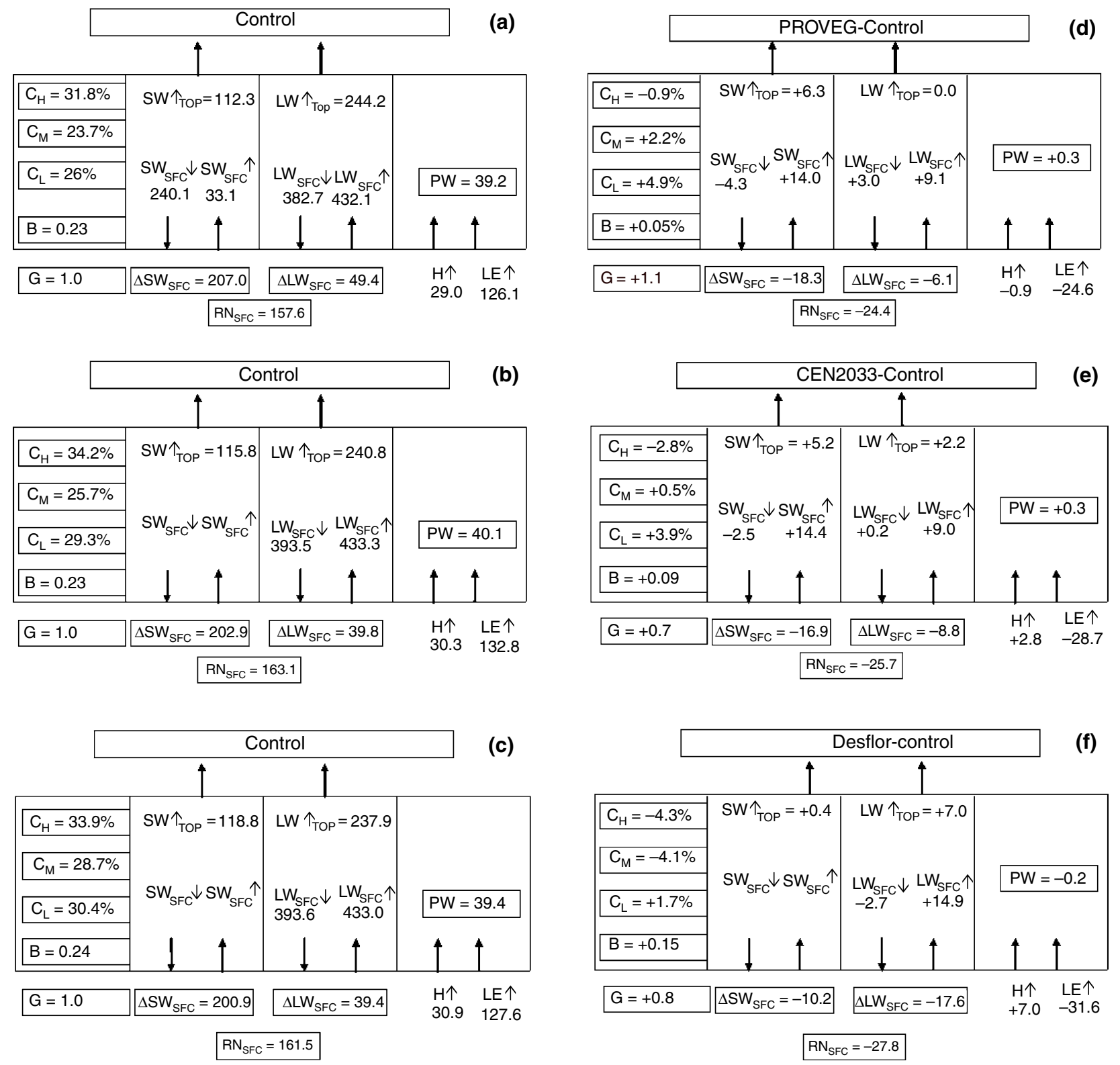

Fig. 6. Schematic illustration of the annual surface and top-of-atmosphere energy budgets for the control experiment and changes for each deforestation scenario: (a, b, c) control experiment for scenarios PROVEG, CEN2033 and DESFLOR, respectively; (d, e, f) absolute changes of the energy budgets for scenarios PROVEG, CEN2033 and DESFLOR, respectively. For control experiment and each scenario, the values correspond to the average of the deforested area. Symbols are as follows: $\mathrm{CH}, \mathrm{CM}, \mathrm{CL}$ are low, middle, and high cloud fractions (in percentage), respectively; $S W_{S F C} \downarrow, S W_{S F C} \uparrow, \Delta S W_{S F C}$, are downward, upward, and net downward shortwave fluxes at surface $\left(\mathrm{W} \mathrm{m}^{-2}\right)$, respectively; $L W_{S F C} \downarrow, L W_{S F C} \uparrow \downarrow, \Delta L W_{S F C}$ are downward, upward, and net longwave downward fluxes at surface $\left(\mathrm{W} \mathrm{m}^{-2}\right) ; R N_{S F C}$ is the net radiation at the surface $\left(\mathrm{W} \mathrm{m}^{-2}\right) ; S W_{T O P} \uparrow, L W_{T O P} \uparrow$ are upward shortwave and longwave fluxes at the top, respectively $\left(\mathrm{W} \mathrm{m}^{-2}\right)$; $\mathrm{PW}$ is the precipitable water (in mm); $B_{o}$ Bowen ratio; $G$ soil heat flux $\left(\mathrm{W} \mathrm{m}^{-2}\right)$ and $H \uparrow$ and $L E \uparrow$ are the surface upward latent and sensible heat fluxes $\left(\mathrm{W} \mathrm{m}^{-2}\right.$ )

to an increase of the cloud cover during the dry season in Amazonia. Using satellite data from the Geostationary Operational Environmental Satellite (GOES) and the Tropical Rainfall Measuring Mission (TRMM), Negri and Adler (2004) observed that during the dry season - when the surface processes are not affected by synoptic scale systems, the low clouds, the deep convection clouds, and the precipitation are more intense over deforested areas of southeast Amazonia, while Chagnon et al. (2004) observed more cloud cover over deforested than over for- 
ested areas of southeast Amazonia during all months of the year. These results are in agreement with several other that were obtained using complex high-resolution models. This shows that the meso-scale circulations, induced by the surface heterogeneity between pasture and forest areas, increase the cloud cover and could induce local precipitation increase (Wang et al. 2000).

The impacts on the energy balance components were more significant when the degree of deforestation increased, being more intense during the dry season, in which the evapotranspiration was limited by the available soil moisture (Table 2). In all of the deforestation scenarios, the increase in surface temperature led to an increase in outgoing long wave radiation; thus, the amount of energy available to be partitioned between the latent heat and the sensible heat fluxes was considerably smaller. In addition, the smaller leaf area index (LAI) and the degraded pasture's reduced soil moisture storage capacity produced a reduction of transpiration and latent heat flux. The reduction in latent heat flux resulted in a large portion of available energy being allocated to heat up the atmosphere over deforested regions. In the PROVEG scenario, for the annual average and the wet season, the latent heat and the sensible heat fluxes decreased, while during the dry season the sensible heat flux presented a slight increase and the latent heat flux was reduced. During the dry season, the reduction of the latent heat flux was greater than the reduction of the surface net radiation, therefore leading to an increase in sensible heat flux. For both CEN2033 and DESFLOR scenarios, the annual means of latent and of sensible heat fluxes decreased and increased, respectively, as shown in Fig. 6. For the DESFLOR scenario, the annual mean of latent heat flux decreased $25 \%$, while the decrease during the dry season was even greater $(28 \%)$. In all scenarios the reduction of the latent heat flux lead to a drier atmosphere near the surface, especially during the dry season, and to a warming of the Planetary Boundary Layer (PBL). This warming is consistent with the reduced roughness length, since the surface roughness plays a fundamental role in determining the turbulent heat and moisture fluxes between the surface and the atmosphere. At the top of the troposphere, the changes in the energy budget components are dominated by changes in the outgoing long wave radiation in the DESFLOR scenario, and by changes in outgoing short wave radiation in both CEN2033 and PROVEG scenarios.

Comparing these results to the measurements analyzed by Von Randow et al. (2004), some differences are observed in relation to the evaporative fraction, defined as the ratio between the latent heat flux and the net radiation (LE/Rn). In all scenarios, the evaporative fraction for the forest was of the order of $80 \%$, while the observational value was about $75 \%$. This means that, in the partition of energy simulated by the model, a greater quantity of energy is available to evaporate the water. At the pasture site, the observed evaporative fraction was approximately $15 \%$ less than the value for the forest, while this study found a reduction of $6 \%$ in all scenarios. Faced with these results, the experiments conducted in this study showed that the reduction in evaporation was not as significant as the reduction observed between the forested and pasture sites.

\section{Water budget}

The evapotranspiration from the tropical forest is one of the most important water vapor sources feeding into precipitation in Amazonia and, as such, it was initially expected that its reduction would lead to a reduction of the precipitation. The changes in the hydrological cycle are different in each one of the deforestation scenarios. For the PROVEG scenario, the annual mean and the wet season precipitation increased 0.6 and $0.7 \mathrm{~mm} \mathrm{day}^{-1}$, respectively, while there were practically no significant changes in the dry season (Table 2). Throughout the year, the moisture convergence and the evapotranspiration were inversely related, that is, most of the reduction of the evapotranspiration was balanced by an increase in moisture convergence $\left(0.37 \mathrm{~mm} \mathrm{day}^{-1}\right)$ during the dry season, while during the wet season, the increase in moisture convergence surpassed the reduced evapotranspiration $\left(-0.31 \mathrm{~mm} \mathrm{day}^{-1}\right)$, resulting an increased precipitation. Similarly, in the CEN2033 scenario the moisture convergence and the evapotranspiration also showed an inverse relationship; overall, during the dry and the wet seasons the reduced evapotranspiration was surpassed by an increase of the moisture 
F. W. S. Correia et al.

convergence. The annual mean and the wet season precipitations increased $0.39 \mathrm{~mm} \mathrm{day}^{-1}$ and $0.42 \mathrm{~mm} \mathrm{day}{ }^{-1}$, respectively. It can be seen that the atmosphere reacted to minimize the effect of the reduced evapotranspiration, bringing more moisture to the deforested area. Although there was a reduction of the evapotranspiration in both PROVEG and CEN2033 scenarios, an increase of the precipitation was observed, due to the continuous interactions of the dynamic and the hydrological processes, which served to compensate the reduction mentioned, with an increase of the local moisture convergence. The negative feedback mechanism of Sud and Fennessy (1984) may be used to explain this result. According to this mechanism, a reduction in evapotranspiration would lead to increases of the surface temperature and the sensible heat flux, which in turn would heat the lower troposphere. This would generate a low thermal surface relative to its neighbors; associated with this low, a low level moisture convergence would occur, creating favorable conditions for precipitation. In addition to this, the warming of the lower troposphere (due to the increase in sensible heat flux) would create a more unstable vertical profile, thus promoting convection.

Similar to the previous scenarios, the moisture convergence and the evapotranspiration also showed an inverse behavior for the DESFLOR scenario; most of the reduction in evapotranspiration is balanced by the increase in moisture convergence. Unlike in the other scenarios, the precipitation decreased during all seasons of the year. The reduced precipitation in this model can be explained by the evapotranspiration mechanism. According to this mechanism, the deforestation reduces the vegetation area and, as a result, the transpiration decreases. Furthermore, the deforestation reduces the interception, which causes a reduction of the evaporation of the water intercepted by the vegetation. The decrease of these components leads to a reduction of the evapotranspiration, leaving the lower troposphere drier. Also, for the convective systems developing over the region, a smaller amount of vapor would be available for vertical transport and the development of precipitation. This reduction in precipitation leads to a reduction in soil moisture, which in turn decreases the evapotranspiration even more. In this scenario, a significant reduc- tion of the evapotranspiration was observed during the dry season, about $20 \%$ greater than the value of the wet season. This is due to the reduced length of roots in the degraded pasture, resulting in less soil moisture availability for evapotranspiration. The reduced evapotranspiration, among other factors, depends on the combination of two effects. First, a reduction in the amount of water being intercepted by plants due to a reduced interception capacity of the forest canopy and the pasture; and second, a change in the annual cycle of forest and pasture transpiration, since the root distribution in pasture areas is shallower than in forested areas, resulting in a significantly reduced evapotranspiration during the dry season. Similar results were reached by Kleidon and Heimann $(1999,2000)$ when they assessed the impact of root depth reduction on regional climate in Amazonia. They observed that the decrease in roots had significant impacts on the regional climate; also, during the dry season there was an accentuated reduction in the amount of energy available for evapotranspiration and, consequently, less moisture for the atmosphere. Further, they observed that for tropical forests an increase in root depth led to increases in evapotranspiration and latent heat flux during the dry season, leading to a surface cooling of the order of $8^{\circ} \mathrm{C}$. In addition, more moisture was transported to areas of intense convective activity and to the ZCIT, thus supplying more energy for convection and, as such, intensifying the tropical circulation pattern.

The reduction in precipitation in the DESFLOR scenario was far less significan than the one found in the other large-scale deforestation experiments for Amazonia. For example, Sud et al. (1996a), Hahmann and Dickinson (1997), and Costa and Foley (2000) found reductions of 1.5, 1.0 and $0.7 \mathrm{~mm} \mathrm{day}^{-1}$, respectively. One possible reason for this difference may be that a regional model is used, which excludes potential largescale feedbacks. Concerning the moisture convergence, the results from all of these experiments showed a reduction in convergence, with the exception of the experiments conducted by Polcher and Laval (1994), Manzi and Planton (1996), and Lean and Rowntree (1997), in which an increase of the moisture convergence was observed. Two methods are suggested for evaluating the hydrological processes in the Amazon 
Modeling the impacts of land cover change in Amazonia
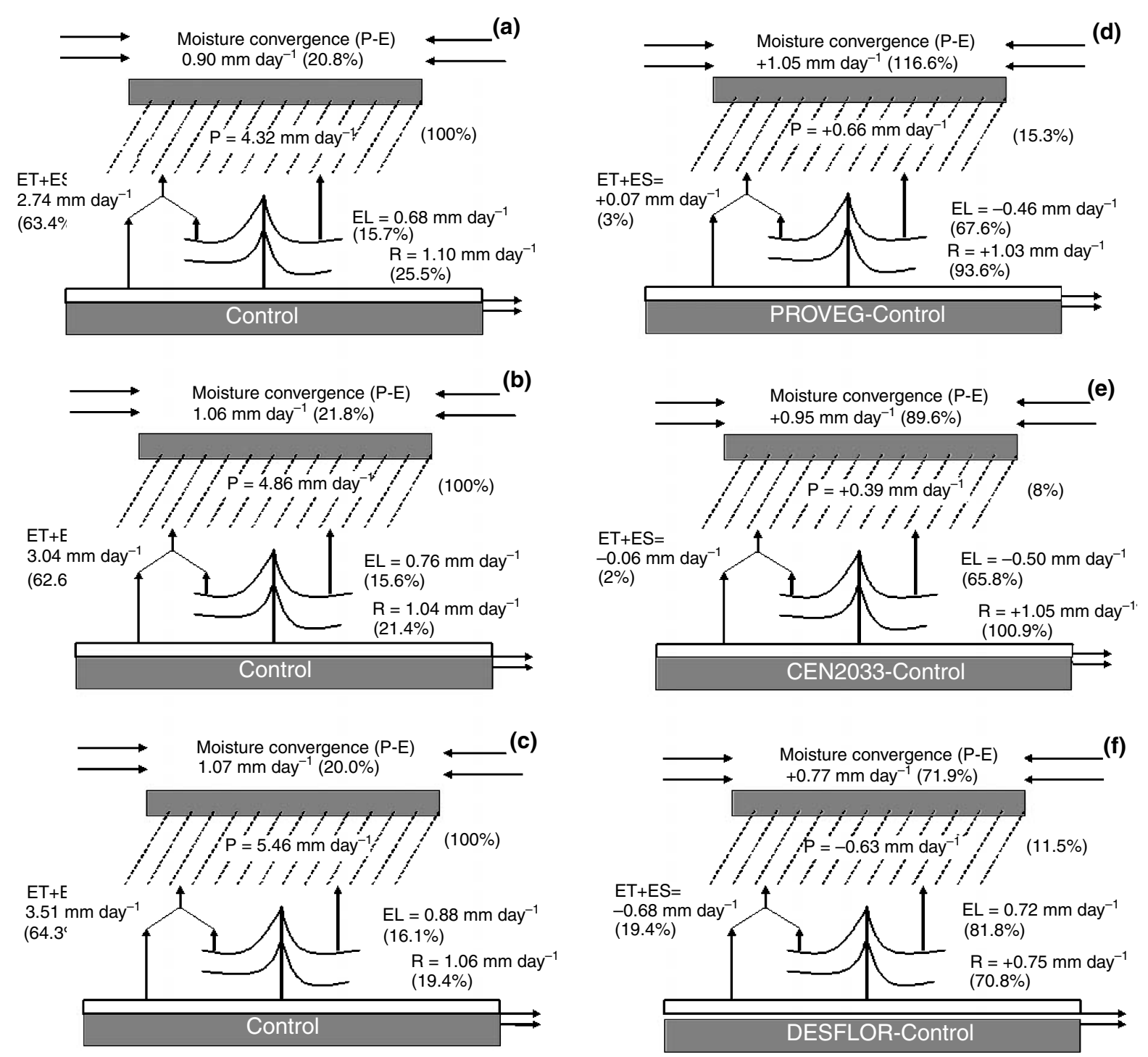

Fig. 7. Schematic illustration of the hydrological cycle in the control experiment and changes for each deforestation scenario: (a-c) control experiments for scenarios PROVEG, CEN2033 and DESFLOR, respectively; (d-f) changes of the hydrological cycle for scenarios PROVEG, CEN2033 and DESFLOR, respectively. For control experiment and each scenario, the values correspond to the average of the deforested area. Here $P$ is the annually averaged precipitation, ET is the transpiration, ES is the soil evaporation $\left(\mathrm{mm} \mathrm{day}^{-1}\right), E L$ is the rate of evaporation of the precipitation intercepted by the foliage, $R$ is the surface runoff. The percentages represent the contribution to the total precipitation. Numbers in parentheses are the percentage changes. Units are in $\mathrm{mm} \mathrm{day}^{-1}$

basin: the first takes into consideration the partition of the precipitation over the basin, and the second evaluates the sources of precipitation, that is, the moisture advection and the local sources (Zhang et al. 1996a, b). In general, the evapotranspiration was approximately $79 \%$ of the total precipitation (Fig. 7). Compared to the previous studies by Salati and Vose (1984) and Salati and Nobre (1991), the model slightly overestimated the local evapotranspiration, but was still close to the values observed in the Amazon Basin's hydrological cycle, and thus capable of representing the impacts that the deforestation scenarios have on the atmospheric water balance in Amazonia.

In all scenarios, the transpiration (ET) plus soil evaporation (ES) was approximately $63 \%$ of the total precipitation as shown in Fig. 7. Additionally, about $15.8 \%$ of the precipitation was intercepted by the forest and re-evaporated back into the atmosphere. These results are compatible with estimates reported by Salati and Nobre 
F. W. S. Correia et al.

(1991); overall, they overestimated $E T+E S$ and underestimated the rate of evaporation of the precipitation intercepted by the foliage $(E L)$. The replacement of forest by pasture in the PROVEG scenario decreased the evapotranspiration $(E T+$ $E L+E S$ ), leading to energy balance changes at the surface and in the atmosphere. The small increase in transpiration plus the soil evaporation were caused by a significant increase in soil evaporation, with an increase of $80 \%$ in relation to the control simulation. For the PROVEG scenario the precipitation increased $15.3 \%$ and changes in the vegetation and the soil parameters led to a reduction of approximately $68 \%$ in the interception loss, being greater than the reduction in transpiration, in relative terms. The total evapotranspiration was reduced by $0.4 \mathrm{~mm}$ day $^{-1}$; however, the external moisture sources increased $1.05 \mathrm{~mm} \mathrm{day}{ }^{-1}(\sim 116 \%)$, showing that in this scenario the horizontal moisture flux over the region overcame the reduction in evapotranspiration. This shows that the negative feedback mechanism prevailed, and it seems to be a better scenario than the one with a positive feedback. The positive feedback mechanism would create an instability in the system, thus leading to further degradation. Similar changes in the hydrological cycle were observed in the CEN2033 scenario. Also caused by changes in the physiological parameters, an $8 \%$ increase in precipitation and a $30 \%$ decrease in transpiration were observed in this simulation. Consequently, changes in physiological parameters in the Amazon forest, such as a reduced leaf area index, are fundamentally important to water recycling changes over the Amazon Basin. The reduction of the evapotranspiration $\left(0.56 \mathrm{~mm} \mathrm{day}^{-1}\right)$ was more significant than with the PROVEG scenario, and the external moisture sources also increased, although less intensely than for the previous case. Notwithstanding, sufficient moisture was transferred to the region leading to an increase of the precipitation. With the large-scale deforestation scenario, the changes in the hydrological cycle were different from the ones observed in the other simulations: the precipitation and the transpiration declined $11 \%$ and $51 \%$, respectively. Also, the external moisture sources increased $(72 \%)$, but they were less intense than in the other scenarios. The negative feedback mechanism was also prevalent in this scenario; however, there was a more significant reduction of the evapotranspiration, resulting in less water being available for precipitation over the deforested area (Fig. 7).

For all scenarios an increase of the surface runoff was observed in the deforested areas. The soil property changes in the deforested area, which reduce the hydraulic conductivity (infiltration), imply an increase of the pasture surface runoff, especially after intense storms. Overall, for the PROVEG and CEN2033 scenarios, the primary factors contributing to the increased runoff were the changes of the distribution and the intensity of precipitation. Hahmann and Dickinson (1997) observed reductions of the runoff and of the soil moisture in root zones for their simulation of large-scale deforestation in Amazonia. According to them, the reduced soil moisture was caused by changes of the root depth and of the soil texture, while the changes in the soil properties, as well as of the precipitation, contributed to the reduction of the runoff. For the DESFLOR scenario the surface runoff increased over the deforested area, with the reduced infiltration rates and the hydraulic soil conductivity being primarily responsible for this increase, since the precipitation decreased over the deforested area. It was observed that the moisture convergence does not match the surface runoff, which possibly indicates that the equilibrium of the model was not completely reached during the numeric integrations.

These results show that up to a certain point the partial deforestation in Amazonia may increase the precipitation at the local scale. However, if the deforestation continues to expand, as has been the case in recent decades, this picture will not remain the same; instead, a moisture deficit will occur in Amazonia, due primarily to a reduction of the water recycling, thus leading to less precipitation. The spatial and seasonal decrease of the precipitation can be associated with longer dry seasons that may lead to serious ecological consequences including, among other things, an increase in the frequency and the intensity of fires in forested areas.

\section{Summary and conclusions}

The consequences of deforestation on the Amazonian regional climate, considering four different 
scenarios (control - no deforestation, PROVEG current scenario, CEN2033 - a deforestation scenario for 2033, and DESFLOR - a large scale deforestation scenario in which the tropical forest in South America was replaced by degraded pasture) are assessed using a regional model (Eta) coupled with the SSiB surface scheme. For each scenario thirteen-month integrations were performed. The simulation results showed significant changes of the radiation and the energy budgets during the dry season, for all scenarios. The decreased root depth after deforestation plays an important role in this result. The reduction of the surface incoming solar radiation for the PROVEG and the CEN2033 scenarios was caused by the increase of the low and medium level cloud cover in the troposphere. Different from previous studies, the effects of the cloud mechanism were not observed for any of the scenarios. Changes in the hydrological cycle differed with each scenario evaluated. For both the deforestation scenarios the net moisture transported into the deforested region was found to increase. For the PROVEG and the CEN2033 scenarios, the increase in moisture convergence was more intense than the reduction of the evapotranspiration, leading to an increase of the local precipitation. In other words, a negative feedback mechanism was observed with these scenarios, in which the mesoescale thermodynamic processes resulting from human-induced heterogeneity played an important role. The negative feedback mechanism discussed by Sud and Fennessy (1984) is useful to explain this process. On the regional scale, the local precipitation increases over the State of Pará with the PROVEG scenario and over the Amazonas (with the CEN2033 scenario) were caused by a local increase of the moisture convergence, thus contributing to modifications in the atmospheric dynamic structure and, consequently, the production of meso-scale circulations caused by the differential heating of the planetary boundary layer (PBL) due to heterogeneity in the underlying surface. These circulations can significantly affect the structure of the PBL, the heat, the moisture and the scalar fluxes, and the cloud and precipitation organizations.

Finally, for the DESFLOR scenario almost $55 \%$ of the reduction in evapotranspiration is compensated by the increase of the moisture con- vergence. This increase is a consequence of two deforestation effects: the planetary boundary layer warming and the wind magnitude increase. Even though the total rainfall decreases, its reduction is much smaller than the reduction of the evapotranspiration. Indeed, if the rainfall reduction were larger than the evapotranspiration reduction, the biosphere could be expected to exert a positive feedback mechanism on the rainfall climatology. Likewise, a smaller reduction would create a negative feedback mechanism. In the present simulation, the biogeophysical feedback mechanism of the deforested Amazonia is negative, and it seems to be a better scenario than the one with a positive feedback; it creates an instability that could lead to further degradation of the biosphere, as inferred by Xue and Shukla (1993) for the Sahel. On the other hand, a negative feedback leads toward a recovery, if the anthropogenic pressure is eliminated. However, for anthropogenic activities, such as the construction of roads, buildings, and parking lots, as well as using the land for grazing or agriculture, which do not permit regrowth, the negative feedback mechanism would generate excess water at the surface, thus causing increased runoff, floodings in low-lying areas, and other hydrologic disasters.

The increase of the cloud cover and the precipitation over the deforested areas (with the PROVEG and CEN2033 scenarios) is another indication that the mesoescale circulations affect the moisture and the heat transport in the atmosphere and, consequently, the climate. These meso-scale processes are sub-grid scale for the GCMs. However, the sub-grid parameterizations for current GCMs are based mostly on turbulence; no mesoescale processes - except gravity waves - are considered. Adequate parameterizations for these processes should be included in GCMs for improved climate simulations. This work shows that failing to account for the surface heterogeneity may have significant implications for simulating land-atmosphere interactions in large-scale atmospheric models.

Therefore, up to a certain point, the partial deforestation in Amazonia may lead to increased rainfall on a local scale; however, if the anthropogenic activities continue to expand, this condition would not be supported, resulting in a reduction of the precipitation. This result means 
F. W. S. Correia et al.

that if the degree of deforestation increases, the moisture convergence will not be intense enough to balance the reduction of the evapotranspiration, thus leading to a drier atmosphere with less precipitation. This, in turn, may lead to a longer dry season. The absence of an extended dry season apparently sustains the current tropical forests, and therefore a lengthening of the dry season could have serious ecological consequences including, among others, the increase of the frequency and the intensity of fires in forest areas. These results suggest that a complete and rapid destruction of the Amazon rainforest could be an irreversible process. Changes in the region's hydrological cycle and the disruption of complex soil-plant-atmosphere relations could be so profound that once the tropical forests were destroyed, they might not be able to reestablish themselves. If conservation policies and sustainable development are not able to halt this increase of the environmental degradation, then the land use changes could alter the vegetation-climate system in a major part of Amazonia leading towards a drier stable equilibrium, in which a different type of vegetation would be adapted to a new climate simulated for the deforestation case, most likely a savannalike vegetation such as the "cerrado" of central Brazil. Two characteristics of such vegetation make it particularly adapted to the foreseeable new climate: it can endure a 6-month dry season and it is fire-adapted.

\section{Ackowledgments}

This work is part of the first author doctoral thesis presented at the Brazilian Institute for Space Research (INPE) under the guidance of the second and third authors, and it was partially supported by grants from the Coordenação de Aperfeiçoamento de Pessoal de Nível Superior (CAPES, first author) and from the Fundação de Amparo à Pesquisa do Estado de São Paulo (FAPESP, Processo 03/00142-8). The authors thank Dr. Britaldo Soares-Filho for both the 2033 and the large scale deforestation scenarios, and Mr. M. Sestini, Eng. E. Kalil and Dr. D. Valeriano, members of the ProVeg Project, for the deforestation current scenario. They thank the Brazilian Center for Weather Forecasting and Climate Studies (CPTEC/INPE) for providing both the computational system (NEC-SX6 supercomputer) to execute the AGCM numerical integrations, and the precipitation data from the automatic meteorological stations of Brazil. The computational assistance from Roberto Rozante and Paulo Kubota is gratefully acknowledged.

\section{References}

Avissar R, Liu Y (1996) Three-dimensional numerical study of shallow convective clouds and precipitation induced by land-surface forcing. J Geophys Res 101: 7499-7518

Avissar R, Schmidt T (1998) An evaluation of the scale at which ground-surface heat flux patchiness affects the convective boundary layer using large-eddy simulations. J Atmos Sci 55: 2666-2689

Betts A, Miller M (1986) A new convective adjustment scheme, part II, Single column model tests using GATE wave, Bomex and artic air-mass data sets. Quart J Roy Meteor Soc 112: 693-709

Black TL (1994) New NMC mesoscale eta model: description and forecasts examples. Weather Forecast 9: 265-278

Chagnon F, Bras R, Wang J (2004) Climatic shift in patterns of shallow clouds over the Amazon. Geophys Res Lett 31(24), No. L24212, 1-4

Chen F, Avissar R (1994a) The impact of land-surface wetness heterogeneity on mesoscale heat fluxes. J Appl Meteor 33: 1323-1340

Chen F, Avissar R (1994b) Impact of land-surface moisture variability on local shallow convective cumulus and precipitation in large-scale models. J Appl Meteor 33: 1382-1401

Chou SC, Tanajura SA, Xue Y, Nobre CA (2002) Validation of the coupled Eta/SSiB model over South America. J Geophys Res 107(D20): doi: 10.1029/2000JD000270

Chu PS, Yu ZP, Hastenrath S (1994) Detecting climatechange concurrent with deforestation in the Amazon Basin - which way has it gone. Bull Amer Meteor Soc 75: 579-583

Correia FWS, Alvalá RCS, Manzi AO, Gielow R, Kubota PY (2005) Calibração do "Simplified Simple Biosphere Model - SSIB" para áreas de pastagem e floresta na Amazônia com dados do LBA (in Portuguese). Acta Amazônica 35(2): 283-297

Costa M, Foley J (2000) Combined effects of deforestation and doubled Atmospheric $\mathrm{CO}_{2}$ concentrations on the climate of Amazonia. J Climate 13: 18-34

Cutrim E, Martin D, Rabin R (1995) Enhancement of cumulus clouds over deforested lands in Amazonia. Bull Amer Meteor Soc 76: 1801-1805

Dalu G, Pielke A, Baldi M, Zheng X (1996) Heat and momentum fluxes induced by thermal inhomogeneities. J Atmos Sci 53: 3286-3320

Dickinson R, Kennedy P (1992) Impacts in regional climate of Amazon deforestation. Geophys Res Lett 19: 1947-1950

Dirmeyer AS, Shukla J (1994) Albedo as a modulator of climate response to tropical deforestation. J Geophys Res 99(D10): 20863-20877

Dorman JL, Sellers P (1989) A global climatology of albedo, roughness length and stomatal resistance for atmospheric general circulation models as represented by the Simple Biosphere Model (SiB). J Appl Meteor 28: 833-855

Durieux L, Machado L, Laurent H (2003) The impact of deforestation on cloud covers over the Amazon arc of deforestation. Remote Sensing Environ 86: 132-140 
FAO (Food and Agriculture Organization of the United Nations) (2000) State of the world's forests. Rome, Italy

Fels SB, Schwarztkopf D (1975) The simplified exchange approximation: a new method for radiative transfer calculations. J Atmos Sci 32: 1475-1488

Gandu AW, Cohen JC, Souza JR (2004) Simulation of deforestation in eastern Amazonia using a high-resolution model. Theor Appl Climatol 78: 123-135

Hahmann AN, Dickinson RE (1997) RCCM2-BATS model over tropical South America: applications to tropical deforestation. J Climate 10: 1944-1964

IBGE (Instituto Brasileiro de Geografia e Estatística) (1993) Mapa de Vegetação do Brasil (in Portuguese) (Mapa Temático. Escala 1:500.000), Rio de Janeiro, Brazil

INPE (Instituto Nacional de Pesquisas Espaciais) (2004) Monitoring the Brazilian Amazon forest by satellite: 2002-2003. (in Portuguese) São José dos Campos, Brazil

INPE (Instituto Nacional de Pesquisas Espaciais) (2005) Monitoring the Brazilian Amazon forest by satellite: 2003-2004. (in Portuguese) São José dos Campos, Brazil

Janjic Z (1979) Forward-backward scheme modified to prevent two-grid-interval noise and its application in sigma coordinate models. Contrib Atmos Phys 50: 186-199

Janjic Z (1984) Nonlinear advection schemes and energy cascade on semi-staggered grids. Mon Wea Rev 112: $1234-1245$

Janowiak J, Xie P (1999) CAMS-OPI: a global satellite-rain gauge merged product for real-time precipitation monitoring applications. J Climate 12: 3335-3342

Kleidon A, Heimann M (1999) Deep-rooted vegetation, Amazonian deforestation, and climate: results from a modelling study. Global Ecol Biogeo 8: 397-405

Kleidon A, Heimann M (2000) Assessing the role of deeprooted vegetation in the climate system with model simulations: mechanism, comparison to observations and implications for Amazonian deforestation. Climate Dyn 16: 183-199

Lacis A, Hansen J (1974) A parameterization of the absorption of solar radiation in the earth's atmosphere. J Atmos Sci 31: 118-133

Lean J, Rowntree P (1997) Understanding the sensitivity of a GCM simulation of Amazonian deforestation to the specification of vegetation and soil characteristics. J Climate 10: $1216-1235$

Li B, Avissar R (1994) The impact of spatial variability of land surface heat fluxes. J Climate 7: 527-537

Lobocki L (1993) A procedure for the derivation of surface layer bulk relationships from simplified second-order closure models. J Appl Meteor 32: 126-138

Lynn B, Rind D, Avissar R (1995) The importance of mesoscale circulations generated by subgrid-scale landscape heterogeneities in general circulation models. J Climate 8: 191-205

Manzi A, Planton S (1996) A simulation of Amazonian deforestation using a GCM calibrated with ABRACOS and ARME data. In: Gash JHC, Nobre CA, Roberts JM, Victoria RL (eds) Amazonian deforestation and climate. John Wiley, Chichester, pp 505-529
McGuffie K, Henderson-Sellers A, Zhang H, Durbidge T, Pitman A (1995) Global climate sensitivity to tropical deforestation. Global Planetary Change 10: 97-128

Mesinger F (1977) Forward-backward scheme, and its use in a limited area model. Contrib Atmos Phys 50: 200-210

Mesinger F (1984) A blocking technique for representation of mountains in atmospheric models. Riv Meteor Aeronáutica 44: 195-202

Mesinger F, Janjic Z, Nickovic S, Gavrilov D, Deaven D (1988) The step-mountain coordinate: model description and performance for cases of alpine lee cyclogenesis and for a case of an Appalachian redevelopment. Mon Wea Rev 116: $1493-1518$

Negri A, Adler R (2004) The impact of Amazonian deforestation on dry season rainfall. J Climate 17: 1306-1319

Nobre CA, Sellers PJ, Shukla J (1991) Amazonian deforestation and regional climate change. J Climate 4: 957-988

Polcher J, Laval K (1994) A statistical study of regional impact of deforestation on climate on the LMD-GCM. Climate Dyn 10: 205-219

Salati E, Nobre CA (1991) Possible climatic impacts of tropical deforestation. Climatic Change 19: 177-196

Salati E, Vose PB (1984) Amazon basin: a system in equilibrium. Science 225: 129-138

Sestini MF, Alvalá RCS, Mello EMK, Valeriano DM, Chan CS, Nobre CA, Paiva JAC, Reimer ES (2002) Elaboração de mapas de vegetação para utilização em modelos meteorológicos e hidrológicos. São José dos Campos, Instituto Nacional de Pesquisas Espaciais (INPE-8972RPQ/730), p 64

Sellers PJ, Minttz Y, Sud YC, Dalcher A (1986) A Simple Biosphere Model $(\mathrm{SiB})$ for use within general circulation model. J Atmos Sci 43(6): 505-531

Silva Dias MAFS, Regnier P (1996) Simulation of mesoescale circulations in a deforested area of Rondônia in dry season. In: Gash JHC, Nobre CA, Roberts JM, Victoria RL (eds) Amazonian deforestation and climate. John Wiley, Chichester, pp 531-547

Slingo JM (1987) The development and verification of a cloud prediction scheme for ECMWF model. Quart J Roy Meteor Soc 113: 899-927

Soares-Filho BS, Alencar A, Nepstad D, Cerqueira G, Diaz M, Rivero S, Solórzanos L, Voll E (2004) Simulating the response of land-cover change to road paving and governance along a major Amazon highway: the SantarémCuiabá corridor. Global Change Biol 10: 745-764, doi: 10.1111/j.1529-8817.2003.00769

Soares-Filho BS, Cerqueira GC, Pennachin C (2002) DINAMICA - a stochastic cellular automata model designed to simulate the landscape dynamics in an Amazonian colonization frontier. Ecol Modelling 154: 217-235

Sud YC, Fennessy MJ (1984) Influence of evaporation in semi-arid on the July circulation: a numerical study. J Climatol 4: 383-398

Sud YC, Walker GK, Kim HL, Linton GE, Sellers PJ, Lau WK (1996a) Biogeophysical consequences of the tropical deforestation Scenario: A GCM simulation Study. J Climate 9: 3225-3247

Sud YC, Yang R, Walker GK (1996b) Impact of in situ deforestation in Amazonia on the regional climate: gen- 
F. W. S. Correia et al.: Modeling the impacts of land cover change in Amazonia

eral circulation model simulation study. J Geophys Res 101(D3): 7095-7109

Voldoire A, Royer JF (2004) Tropical deforestation and climate variability. Climate Dyn 22: 857-874

Von Randow C, Manzi A, Kruijt B, Oliveira P, Zanchi F, Silva R, Hodnett M, Gash J, Elbers J, Waterloo M, Cardoso F, Kabat P (2004) Comparative measurements and seasonal variations in energy and carbon exchange over forest and pasture in South West Amazonia. Theor Appl Climatol 78: 5-26

Wang J, Bras R, Eltahir A (2000) The impact of observed deforestation on the mesoscale distribution of rainfall and clouds in Amazonia. J Hydrometeor 1: 267-286

Weaver C, Avissar R (2002) Atmospheric disturbances caused by human modification of the landscape. Bull Amer Meteor Soc 82: 269-281
Wetzel P, Argentini S, Boone A (1996) Role of land surface in controlling daytime cloud amount: two case studies in the GCIP-SW area. J Geophys Res 101: 7359-7370

Xue Y, Shukla J (1993) The influence of land surface properties on Sahel climate, I, desertification. J Climate 6: 2232-2245

Xue Y, Sellers PJ, Kinter JL, Shukla J (1991) A simplified biosphere model for global climate studies. J Climate 4: 345-364

Zhang H, McGuffie K, Henderson-Sellers A (1996a) Impacts of tropical deforestation. Part I: Process analysis of local climatic change. J Climate 9: 1497-1517

Zhang H, McGuffie K, Henderson-Sellers A (1996b) Impacts of tropical deforestation. Part II: The role of large-scale dynamics. J Climate 9: 2498-2521 